\title{
Trends in prostate biopsy in Ontario, 1992-2014: a cohort study
}

\author{
Luke T. Lavallée MDCM, Rodney H. Breau MD, Dean Fergusson PhD, Carl van Walraven MD
}

\section{Abstract}

Background: Prostate cancer is a substantial public health concern; however, in recent years, national guidelines have recommended against prostate cancer screening. We sought to determine if prostate biopsy incidence has changed over time in Ontario. We hypothesized that there has been a decrease in the incidence of prostate biopsy in recent years.

Methods: This cohort study used population-based administrative databases from Ontario, Canada. We used a diagnostic code to identify if a patient received his first prostate biopsy between 1992 and 2012 (the last year for which records in the Ontario Cancer Registry were complete). Age-stratified and overall age-standardized incidences of prostate biopsy were determined. Changes over time in prostate biopsy incidence and the proportion of prostate biopsies that showed malignant disease were examined using negative binomial regression adjusting for patient age.

Results: We identified 231266 Ontario men aged 40 years and older who received their first prostate biopsy between 1992 and 2014. Up to 2007, biopsy incidence increased in younger men, but decreased in older men. After 2007, biopsy incidence decreased in all age groups, with the age-standardized overall biopsy incidence dropping from 480 per 100000 in 2007 to 250 per 100000 in 2014 . A total of 84149 (39\%) incident biopsies showed malignant disease. The proportion of biopsies classified as showing malignant disease increased during the study period, from $25.6 \%$ in 1992 to $49.2 \%$ in 2010 , and then decreased in all age groups.

Interpretation: Previously increasing biopsy rates decreased significantly in recent years, suggesting that prostate cancer screening in Ontario may be changing.

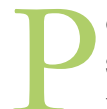
opulation-based prostate cancer screening with prostatespecific antigen (PSA) has been associated with a dramatic increase in the number of diagnosed prostate cancers and a decrease in the number of advanced prostate cancers and prostate cancer-specific mortality. ${ }^{1,2}$ Although screening results in early disease detection, some tumours found through screening are indolent. Randomized controlled studies have shown that screening does not benefit all men., Because prostate cancer screening may lead to overdiagnosis and has unclear benefits, some groups have recommended against screening for all men. ${ }^{5,6}$

The definitive diagnosis of prostate cancer is usually made by performing a transrectal ultrasound-guided prostate biopsy. The indications for prostate biopsy are poorly defined, but it is usually prompted by an abnormally elevated PSA blood concentration or abnormal physical examination (i.e., digital rectal examination). Previously, many men underwent a biopsy if there was any elevation in PSA above a normal threshold. Currently, physicians may be more discriminative in selecting patients for biopsy by using other results, such as PSA density, PSA Free-Total ratio, age-specific PSA thresholds or repeat PSA testing. ${ }^{7}$ One would expect that the use of these ancillary factors, in addition to more refined patient selection for screening, would decrease the number of prostate biopsies being performed over time.

We hypothesized that the incidence of prostate biopsy decreased due to a lack of clear benefit of prostate cancer screening, more selective biopsy referrals by physicians and a greater awareness of the risks of overdiagnosis and overtreatment of prostate cancer. We also hypothesized that more careful selection of men for biopsy has increased the proportion of biopsies that show malignant disease. The objective of this population-based study was to describe trends in the use of prostate biopsy in Ontario to determine if physician practices are changing.

Competing interests: Luke Lavallée has participated in ad boards with Sanofi and Ferring and has received grants from Sanofi.

This article has been peer reviewed.

Correspondence to: Luke Lavallée, lulavallee@toh.ca

CMAJ Open 2016. DOI:10.9778/cmajo.20160079 


\section{Methods}

\section{Design and data sets}

This study used population-based administrative data sets from Ontario. Ontario has a population of about 14 million people and has a public health care system. Data sets used for this study included the Ontario Health Insurance Plan (OHIP) database, which captures all remunerated health care services provided in Ontario recording patient identifiers, physician identifiers, service date, and service identifier; the Registered Persons Database, which records demographic information and date of death for all Ontarians; and the Ontario Cancer Registry, which records all primary cancer diagnoses and their diagnosis source. ${ }^{8}$ These databases were linked deterministically using encrypted health care numbers.

\section{Study cohort}

We identified all prostate biopsies performed in Ontario using a diagnostic code for prostate biopsy (code Z712) in the OHIP database. We previously found that the prostate biopsy code had a sensitivity of $86 \%$ and specificity of more than $95 \%$ for identifying first prostate biopsies. ${ }^{9}$ The operating characteristics of the code varied during the study period. We therefore performed a sensitivity analysis to determine if changes in code characteristics affected biopsy incidence trends and found no difference. ${ }^{9}$

Some patients receive more than 1 prostate biopsy for cancer detection, and other patients receive more than 1 biopsy after their diagnosis of cancer as part of an active surveillance program. The purpose of this study was to examine prostate biopsy incidence in the context of screening and initial diagnosis; therefore, the study cohort was limited to a patient's first prostate biopsy.

We used the Registered Persons Database to determine each patient's age at the time of biopsy and excluded patients who were less than 40 years of age because these patients are not typically included in screening cohorts. We used the Ontario Cancer Registry to identify patients who had a diagnosis of prostate cancer before their biopsy; these patients were also excluded.

\section{Analysis}

We determined the annual number and incidence of first prostate biopsy from 1992 to 2014. Biopsy incidence was stratified into decade-wide age groups, with all men over the age of 90 years grouped together. The incidence numerator was the number of men having a prostate biopsy in each year within each age group; the denominator was the number of men in that age group alive at the start of the year, determined using intercensal population estimates from Statistics Canada. ${ }^{10}$ Because the age structure of Ontario changed during the study period, overall annual biopsy incidence was age-standardized with direct methods using the age-group strata for all Ontario men between 1992 and 2014 as the standard population.

We modelled changes in prostate biopsy incidence over time using negative binomial regression with PROC GENMOD (SAS version 9.3). These models included terms for year and patient age and accounted for the number of men at risk within each year. The exponent of the difference between each year's parameter estimate and that for 1992 (the reference year) returned the incidence density ratio (IDR). The IDR is interpreted similarly to a relative risk.

We linked to the Ontario Cancer Registry to determine the malignant status of each biopsy. A biopsy was classified as showing malignant disease if a diagnosis of prostate cancer was recorded in the Ontario Cancer Registry within 1 week of the biopsy date. This 1 week period permitted variation in the method and timing used by clinicians for submitting claims to the OHIP and variation in the dates recorded by pathologists when attributing the diagnosis date. If a diagnosis of cancer was not identified in the Ontario Cancer Registry within this period, the biopsy was classified as benign. The Ontario Cancer Registry is complete between 1992 and 2012; therefore, analyses regarding malignant disease were limited to these years. The proportion of prostate biopsies showing malignant disease was determined for each study year and age group. Preplanned sensitivity analyses were performed to see if changing the period before and after biopsy during which a diagnosis of cancer could be captured in the Ontario Cancer Registry would change the number of biopsies that were classified as showing malignant disease. Periods of 14, 21, 28 and 35 days were analyzed. The number of cancer diagnoses for each time frame was compared. A change in the absolute number of cancer diagnoses of more than $1 \%$ was considered significant.

Negative binomial regression was used to determine the influence of year on the proportion of malignancies over time, adjusting for patient age. In this model, the IDR represents the risk of malignant disease at first prostate biopsy in 1 year relative to the risk in the comparison year.

\section{Ethics approval}

The study was approved by our institutional research ethics board.

\section{Results}

\section{2-2014}

A total of 346287 prostate biopsy claims were identified in the OHIP database between 1992 and 2014. A total of 115021 $(33.2 \%)$ biopsies were excluded for the following reasons: 99047 (86.1\%) biopsies were performed in men who had previously undergone prostate biopsy; 11519 (10.0\%) biopsies were done in patients who had a diagnosis of prostate cancer in the Ontario Cancer Registry before their first biopsy; 3749 (3.3\%) were duplicate codes (same patient and date); and 706 $(0.6 \%)$ were in patients under the age of 40 years.

During the study period, 231266 Ontario men aged 40 years and older had a first prostate biopsy between 1992 and 2014 (Table 1 and Appendix 1, available at www.cmajopen. $\mathrm{ca} /$ content/4/4/E698/suppl/DC1). A mean of 10055 biopsies were performed per year, with the greatest number performed in 2007 and in men aged 60-69 years. Up to 2007, biopsy incidence increased in younger men, but decreased in older men (Figure 1). For example, biopsy incidence in men 


\section{OPEN}

aged 50-59 years was 164 per 100000 men in 1992 and 444 per 100000 men in 2007. Conversely, the incidence of biopsy in men aged 80-89 years was 696 per 100000 men in 1992 and 422 per 100000 men in 2014. After 2007, however, prostate biopsy incidence decreased in all age groups, with the age-standardized overall biopsy rate dropping from 480 per 100000 in 2007 to 250 per 100000 in 2014 (Figure 1). Biopsy incidence notably exceeded that in 1992 after 2000, with significant excesses between 2005 and 2008 (Figure 2). After 2008, however, age-adjusted biopsy incidence decreased and was significantly below 1992 levels after 2012 (Figure 2).

\section{2-2012}

Up to 2012, 213095 men had a first prostate biopsy, with 84 149 (39\%) classified as showing malignant disease (Table 2). This proportion did not change notably when the surveillance time frame changed from within 7 days to within 35 days before or after the biopsy. The proportion of biopsies classi- fied as showing malignant disease increased during the study period, from $25.6 \%$ in 1992 to a high of $49.2 \%$ in 2010, and then dropped slightly in all age groups (Figure 3). The ageadjusted incidence of the prostate biopsy showing malignant disease increased significantly to 2010 (IDR 2.09, 95\% confidence interval [CI] 1.98-2.21) (Figure 4). The rate of malignant disease decreased subsequently, but remained significantly higher than that of 1992 .

\section{Interpretation}

We examined prostate biopsy over time at a population-based level. We identified several noteworthy trends, including a significant decrease in biopsy incidence when recommendations against prostate cancer screening were made, a notable interaction between biopsy and patient age (with increased use in younger men, but decreased use in older men) and an overall increased proportion of biopsies resulting in a diagnosis of cancer.

Table 1: Age-stratified prostate biopsy incidence per 100000 males in Ontario from 1992-2014

\begin{tabular}{|c|c|c|c|c|c|c|c|c|c|}
\hline \multirow[b]{2}{*}{ Year } & \multicolumn{6}{|c|}{ Age group, no. (\%) } & \multirow{2}{*}{$\begin{array}{l}\text { Year total, } \\
\text { no. }\end{array}$} & \multirow[b]{2}{*}{$\%$ in year } & \multirow{2}{*}{$\begin{array}{c}\text { Overall } \\
\text { age- } \\
\text { standardized } \\
\text { rate }\end{array}$} \\
\hline & $40-49$ & $50-59$ & $60-69$ & $70-79$ & 80-89 & $\geq 90$ & & & \\
\hline 1992 & $19(0.7)$ & $164(6.3)$ & $627(24.1)$ & $906(34.8)$ & $696(26.7)$ & $194(7.4)$ & 2606 & 4.4 & 317 \\
\hline 1993 & $23(0.8)$ & $212(7.5)$ & 757 (26.6) & $1014(35.7)$ & $649(22.8)$ & $186(6.5)$ & 2841 & 4.8 & 368 \\
\hline 1996 & $25(1.0)$ & $233(9.6)$ & $750(30.8)$ & $872(35.8)$ & $448(18.4)$ & $111(4.6)$ & 2439 & 4.1 & 346 \\
\hline 1997 & $27(1.0)$ & $282(9.9)$ & $870(30.7)$ & $1002(35.3)$ & $508(17.9)$ & $149(5.3)$ & 2838 & 4.8 & 403 \\
\hline 1998 & $29(1.1)$ & 266 (9.9) & 801 (29.9) & $894(33.4)$ & $574(21.4)$ & $116(4.3)$ & 2680 & 4.5 & 376 \\
\hline 1999 & $28(1.0)$ & $274(10.1)$ & 777 (28.7) & 844 (31.1) & $497(18.3)$ & $291(10.7)$ & 2711 & 4.5 & 364 \\
\hline 2002 & $38(1.3)$ & $345(12.1)$ & 911 (32.1) & $880(31.0)$ & $514(18.1)$ & $152(5.4)$ & 2840 & 4.8 & 418 \\
\hline 2003 & $40(1.5)$ & $350(12.8)$ & 884 (32.4) & 839 (30.7) & 469 (17.2) & $150(5.5)$ & 2732 & 4.6 & 407 \\
\hline 2004 & $40(1.5)$ & $373(13.7)$ & $892(32.7)$ & $843(30.9)$ & $438(16.0)$ & $144(5.3)$ & 2730 & 4.6 & 415 \\
\hline 2005 & $49(1.6)$ & 409 (13.6) & 1017 (33.8) & 924 (30.7) & 469 (15.6) & $144(4.8)$ & 3012 & 5 & 464 \\
\hline 2006 & $55(1.8)$ & 433 (13.9) & 1045 (33.6) & $928(29.8)$ & $429(13.8)$ & $224(7.2)$ & 3114 & 5.2 & 477 \\
\hline 2007 & $54(1.8)$ & $444(14.7)$ & $1050(34.7)$ & 937 (30.9) & $422(13.9)$ & $121(4.0)$ & 3028 & 5.1 & 480 \\
\hline 2008 & $57(2.2)$ & $389(15.0)$ & $885(34.1)$ & 815 (31.4) & $359(13.8)$ & $90(3.5)$ & 2595 & 4.3 & 416 \\
\hline 2009 & $58(2.3)$ & $391(15.5)$ & $893(35.4)$ & $780(30.9)$ & $328(13.0)$ & $75(3.0)$ & 2525 & 4.2 & 413 \\
\hline 2010 & $56(2.3)$ & $350(14.7)$ & $837(35.1)$ & 752 (31.5) & $321(13.4)$ & $72(3.0)$ & 2388 & 4 & 386 \\
\hline
\end{tabular}


We found that overall prostate biopsy incidence increased from 1992 to 2007 and decreased thereafter. Significant decreases in prostate biopsy incidence were seen in men around 2008, which corresponds with the 2008 US Preventive Services Task Force guideline recommendation against PSA screening in older men. ${ }^{11} \mathrm{~A}$ steeper drop off in all age groups was seen in 2012, which corresponds with the 2012 US Preventive Services Task Force guideline against screening in all men. ${ }^{5}$ These findings are consistent with use of PSA screening and cancer incidence during this time and show that screening guidelines may have changed how physicians practise. ${ }^{12,13}$

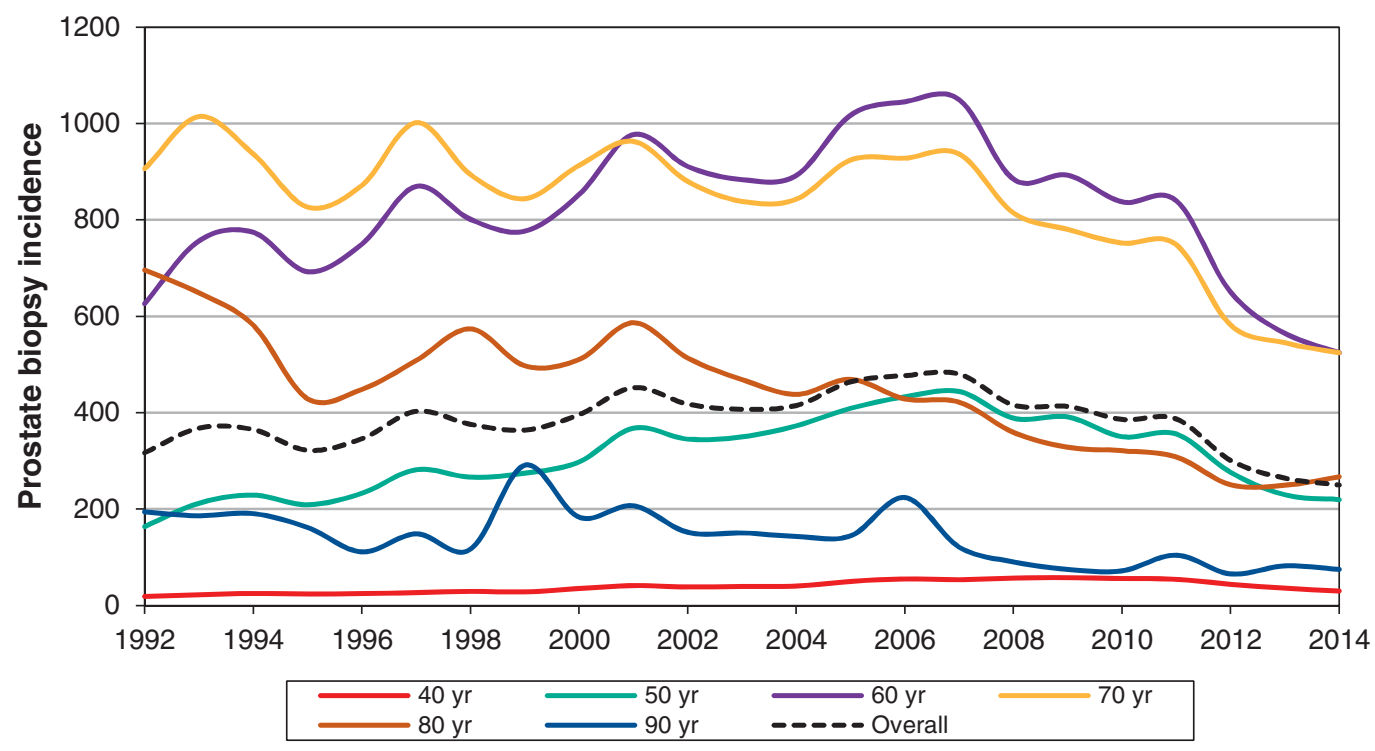

Figure 1: Incidence of prostate biopsy in Ontario from 1992-2014 stratified by age group per 100000 men. Note: Lines between years were smoothed with spline function.

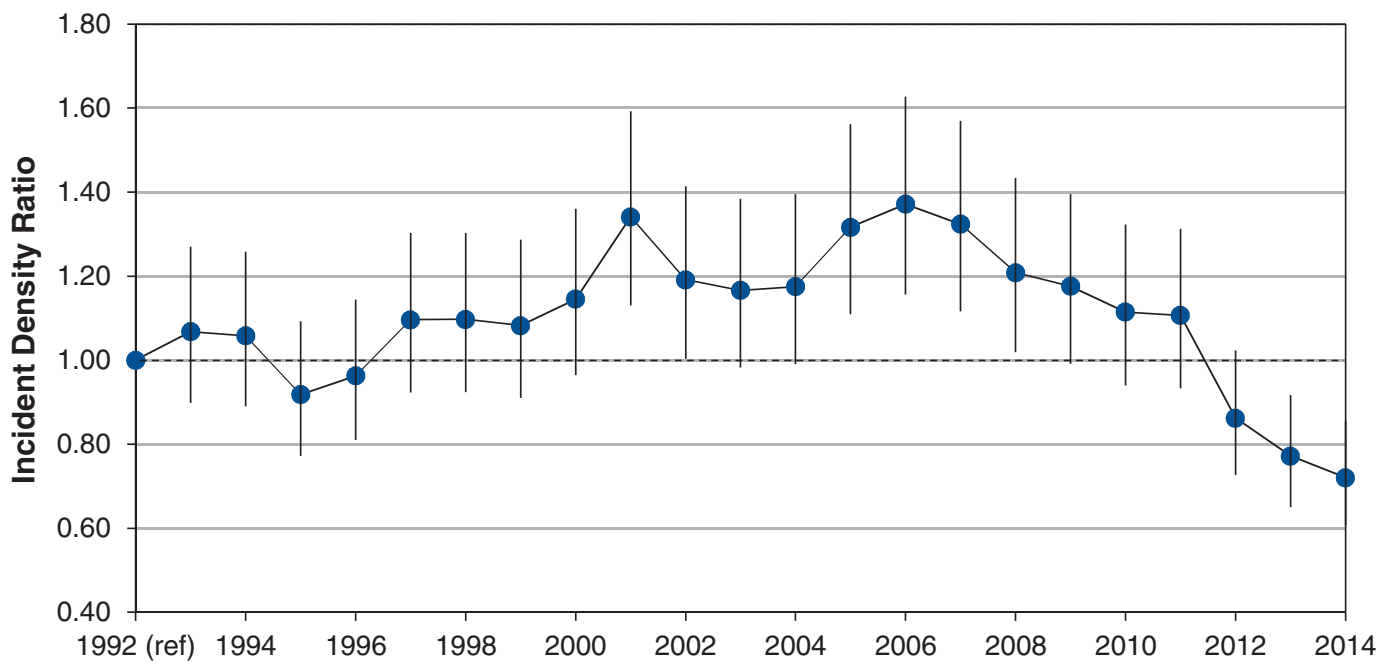

Figure 2: Annual age-adjusted prostate biopsy rate in Ontario 1992-2014. 


\section{OPEN}

Research

These data provide indirect evidence that PSA screening rates have decreased in Ontario. We are unable to directly measure PSA screening rates, because PSA tests are not captured in current administrative data sets. However, because prostate biopsies are the end result of screening, biopsy trends are likely indicative of screening practices; a study involving more than 300000 men in Denmark reported that men in the highest quartile of PSA screening intensity were $76 \%$ more likely to receive a prostate biopsy than men in the lowest quartile. ${ }^{14}$ Furthermore, biopsy trends in our study are consistent with several studies that report decreased use of PSA screening after the US Preventive Services Task Force

\begin{tabular}{|c|c|c|c|c|c|c|c|c|c|}
\hline \multirow[b]{2}{*}{ Year } & \multicolumn{6}{|c|}{ Age group, no. (\%) } & \multirow[b]{2}{*}{ Cancer, \% } & \multirow[b]{2}{*}{ Cancer, no. } & \multirow[b]{2}{*}{ Biopsy, no } \\
\hline & $40-49$ & $50-59$ & $60-69$ & $70-79$ & $80-89$ & $\geq 90$ & & & \\
\hline 1992 & $\begin{array}{c}10 \\
(7.4)\end{array}$ & $\begin{array}{c}124 \\
(15.3)\end{array}$ & $\begin{array}{c}612 \\
(23.4)\end{array}$ & $\begin{array}{c}677 \\
(31.4)\end{array}$ & $\begin{array}{c}171 \\
(32.2)\end{array}$ & $\begin{array}{c}7 \\
(38.9)\end{array}$ & 25.6 & 1601 & 6263 \\
\hline 1993 & $\begin{array}{c}12 \\
(7.1)\end{array}$ & $\begin{array}{c}195 \\
(18.2)\end{array}$ & $\begin{array}{c}841 \\
(26.4)\end{array}$ & $\begin{array}{c}784 \\
(31.5)\end{array}$ & $\begin{array}{c}197 \\
(38.2)\end{array}$ & $\begin{array}{c}8 \\
(44.4)\end{array}$ & 27.3 & 2037 & 7456 \\
\hline 1994 & $\begin{array}{c}23 \\
(12.0)\end{array}$ & $\begin{array}{c}268 \\
(22.6)\end{array}$ & $\begin{array}{c}912 \\
(27.8)\end{array}$ & $\begin{array}{c}786 \\
(33.1)\end{array}$ & $\begin{array}{c}178 \\
(36.9)\end{array}$ & $\begin{array}{c}3 \\
(15.8)\end{array}$ & 28.8 & 2170 & 7541 \\
\hline 1995 & $\begin{array}{c}19 \\
(10.1)\end{array}$ & $\begin{array}{c}256 \\
(23.1)\end{array}$ & $\begin{array}{c}846 \\
(28.6)\end{array}$ & $\begin{array}{c}777 \\
(36.0)\end{array}$ & $\begin{array}{c}152 \\
(41.0)\end{array}$ & $\begin{array}{c}7 \\
(43.8)\end{array}$ & 30.3 & 2057 & 6801 \\
\hline 1996 & $\begin{array}{c}31 \\
(15.5)\end{array}$ & $\begin{array}{c}318 \\
(24.9)\end{array}$ & $\begin{array}{c}1017 \\
(31.6)\end{array}$ & $\begin{array}{c}886 \\
(37.7)\end{array}$ & $\begin{array}{c}163 \\
(40.8)\end{array}$ & $\begin{array}{c}6 \\
(54.6)\end{array}$ & 32.4 & 2421 & 7462 \\
\hline 1997 & $\begin{array}{c}32 \\
(14.4)\end{array}$ & $\begin{array}{c}413 \\
(25.3)\end{array}$ & $\begin{array}{c}1123 \\
(29.8)\end{array}$ & $\begin{array}{c}1058 \\
(37.8)\end{array}$ & $\begin{array}{c}180 \\
(39.0)\end{array}$ & $\begin{array}{c}7 \\
(46.7)\end{array}$ & 31.6 & 2813 & 8897 \\
\hline 1998 & $\begin{array}{c}37 \\
(14.8)\end{array}$ & $\begin{array}{c}424 \\
(26.1)\end{array}$ & $\begin{array}{c}1176 \\
(33.7)\end{array}$ & $\begin{array}{c}1037 \\
(40.0)\end{array}$ & $\begin{array}{c}228 \\
(43.1)\end{array}$ & $\begin{array}{c}6 \\
(50.0)\end{array}$ & 34.2 & 2908 & 8494 \\
\hline 1999 & $\begin{array}{c}51 \\
(20.6)\end{array}$ & $\begin{array}{c}481 \\
(27.6)\end{array}$ & $\begin{array}{c}1240 \\
(36.3)\end{array}$ & $\begin{array}{c}1088 \\
(43.1)\end{array}$ & $\begin{array}{c}212 \\
(45.4)\end{array}$ & $\begin{array}{c}17 \\
(54.8)\end{array}$ & 36.7 & 3089 & 8424 \\
\hline 2000 & $\begin{array}{c}61 \\
(19.4)\end{array}$ & $\begin{array}{c}607 \\
(30.8)\end{array}$ & $\begin{array}{c}1455 \\
(38.6)\end{array}$ & $\begin{array}{c}1299 \\
(46.4)\end{array}$ & $\begin{array}{c}270 \\
(53.6)\end{array}$ & $\begin{array}{c}10 \\
(50.0)\end{array}$ & 39.5 & 3702 & 9378 \\
\hline 2001 & $\begin{array}{c}72 \\
(18.6)\end{array}$ & $\begin{array}{c}763 \\
(30.1)\end{array}$ & $\begin{array}{c}1712 \\
(39.3)\end{array}$ & $\begin{array}{c}1447 \\
(47.8)\end{array}$ & $\begin{array}{c}314 \\
(50.8)\end{array}$ & $\begin{array}{c}9 \\
(39.1)\end{array}$ & 39.4 & 4317 & 10955 \\
\hline 2002 & $\begin{array}{c}88 \\
(23.7)\end{array}$ & $\begin{array}{c}717 \\
(29.0)\end{array}$ & $\begin{array}{c}1573 \\
(38.0)\end{array}$ & $\begin{array}{c}1313 \\
(46.5)\end{array}$ & $\begin{array}{c}280 \\
(48.5)\end{array}$ & $\begin{array}{c}10 \\
(55.6)\end{array}$ & 38.3 & 3981 & 10401 \\
\hline 2003 & $\begin{array}{c}84 \\
(21.2)\end{array}$ & $\begin{array}{c}728 \\
(28.1)\end{array}$ & $\begin{array}{c}1533 \\
(37.2)\end{array}$ & $\begin{array}{c}1216 \\
(44.5)\end{array}$ & $\begin{array}{c}284 \\
(50.8)\end{array}$ & $\begin{array}{c}6 \\
(31.6)\end{array}$ & 37 & 3851 & 10416 \\
\hline 2004 & $\begin{array}{c}105 \\
(25.2)\end{array}$ & $\begin{array}{c}969 \\
(33.9)\end{array}$ & $\begin{array}{c}1701 \\
(39.7)\end{array}$ & $\begin{array}{c}1399 \\
(50.4)\end{array}$ & $\begin{array}{c}314 \\
(56.9)\end{array}$ & $\begin{array}{c}10 \\
(52.6)\end{array}$ & 41.2 & 4498 & 10909 \\
\hline 2005 & $\begin{array}{c}136 \\
(26.2)\end{array}$ & $\begin{array}{c}1067 \\
(32.8)\end{array}$ & $\begin{array}{c}2039 \\
(40.6)\end{array}$ & $\begin{array}{c}1525 \\
(49.6)\end{array}$ & $\begin{array}{c}367 \\
(58.6)\end{array}$ & $\begin{array}{c}11 \\
(55.0)\end{array}$ & 41.1 & 5145 & 12515 \\
\hline 2006 & $\begin{array}{c}149 \\
(25.4)\end{array}$ & $\begin{array}{c}1226 \\
(34.4)\end{array}$ & $\begin{array}{c}2305 \\
(43.1)\end{array}$ & $\begin{array}{c}1623 \\
(52.1)\end{array}$ & $\begin{array}{c}336 \\
(55.5)\end{array}$ & $\begin{array}{c}20 \\
(60.6)\end{array}$ & 42.7 & 5659 & 13255 \\
\hline 2007 & $\begin{array}{c}155 \\
(27.3)\end{array}$ & $\begin{array}{c}1312 \\
(35.2)\end{array}$ & $\begin{array}{c}2484 \\
(43.6)\end{array}$ & $\begin{array}{c}1631 \\
(51.2)\end{array}$ & $\begin{array}{c}383 \\
(61.7)\end{array}$ & $\begin{array}{c}14 \\
(73.7)\end{array}$ & 43.3 & 5979 & 13823 \\
\hline 2008 & $\begin{array}{c}171 \\
(28.6)\end{array}$ & $\begin{array}{c}1325 \\
(39.5)\end{array}$ & $\begin{array}{c}2354 \\
(46.6)\end{array}$ & $\begin{array}{c}1612 \\
(57.3)\end{array}$ & $\begin{array}{c}347 \\
(62.9)\end{array}$ & $\begin{array}{c}13 \\
(86.7)\end{array}$ & 47 & 5822 & 12383 \\
\hline 2009 & $\begin{array}{c}166 \\
(27.6)\end{array}$ & $\begin{array}{c}1322 \\
(38.1)\end{array}$ & $\begin{array}{l}2526 \\
(47.4)\end{array}$ & $\begin{array}{c}1604 \\
(58.4)\end{array}$ & $\begin{array}{c}369 \\
(70.4)\end{array}$ & $\begin{array}{c}8 \\
(61.5)\end{array}$ & 47.3 & 5995 & 12684 \\
\hline 2010 & $\begin{array}{c}178 \\
(31.1)\end{array}$ & $\begin{array}{c}1272 \\
(39.7)\end{array}$ & $\begin{array}{c}2546 \\
(48.8)\end{array}$ & $\begin{array}{c}1625 \\
(60.3)\end{array}$ & $\begin{array}{c}395 \\
(74.3)\end{array}$ & $\begin{array}{c}10 \\
(71.4)\end{array}$ & 49.2 & 6026 & 12239 \\
\hline 2011 & $\begin{array}{c}169 \\
(30.7)\end{array}$ & $\begin{array}{c}1261 \\
(37.6)\end{array}$ & $\begin{array}{c}2544 \\
(46.7)\end{array}$ & $\begin{array}{c}1600 \\
(58.4)\end{array}$ & $\begin{array}{c}364 \\
(68.8)\end{array}$ & $\begin{array}{c}18 \\
(78.3)\end{array}$ & 47.1 & 5956 & 12650 \\
\hline 2012 & $\begin{array}{c}107 \\
(24.4)\end{array}$ & $\begin{array}{c}890 \\
(33.3)\end{array}$ & $\begin{array}{l}1795 \\
(1.0)\end{array}$ & $\begin{array}{c}1066 \\
(48.7)\end{array}$ & $\begin{array}{c}254 \\
(56.8)\end{array}$ & $\begin{array}{c}10 \\
(62.5)\end{array}$ & 40.6 & 4122 & 10149 \\
\hline $\begin{array}{l}\text { Mean for study } \\
\text { period }\end{array}$ & $\begin{array}{c}88 \\
(20.5)\end{array}$ & $\begin{array}{c}759 \\
(29.8)\end{array}$ & $\begin{array}{l}1635 \\
(37.5)\end{array}$ & $\begin{array}{c}1241 \\
(45.8)\end{array}$ & $\begin{array}{c}274 \\
(51.7)\end{array}$ & $\begin{array}{c}10 \\
(53.7)\end{array}$ & 38.1 & 4007 & 10147 \\
\hline
\end{tabular}


recommendation. ${ }^{12,13,15}$ In a study at a large tertiary care centre in Toronto, the median number of patients having their first biopsy almost halved from a median of 42.5 (interquartile range [IQR] 37.5-45.5) to 24.0 (IQR 19.0-32.5) per month before and after the US Preventive Services Task
Force recommendation in 2012. ${ }^{16}$ These authors concluded that the decrease in biopsies that they saw was likely due to decreased use of PSA screening in their catchment area.

We found that decreases in biopsy use were most prominent in men over the age of 70 years. As a result, younger men

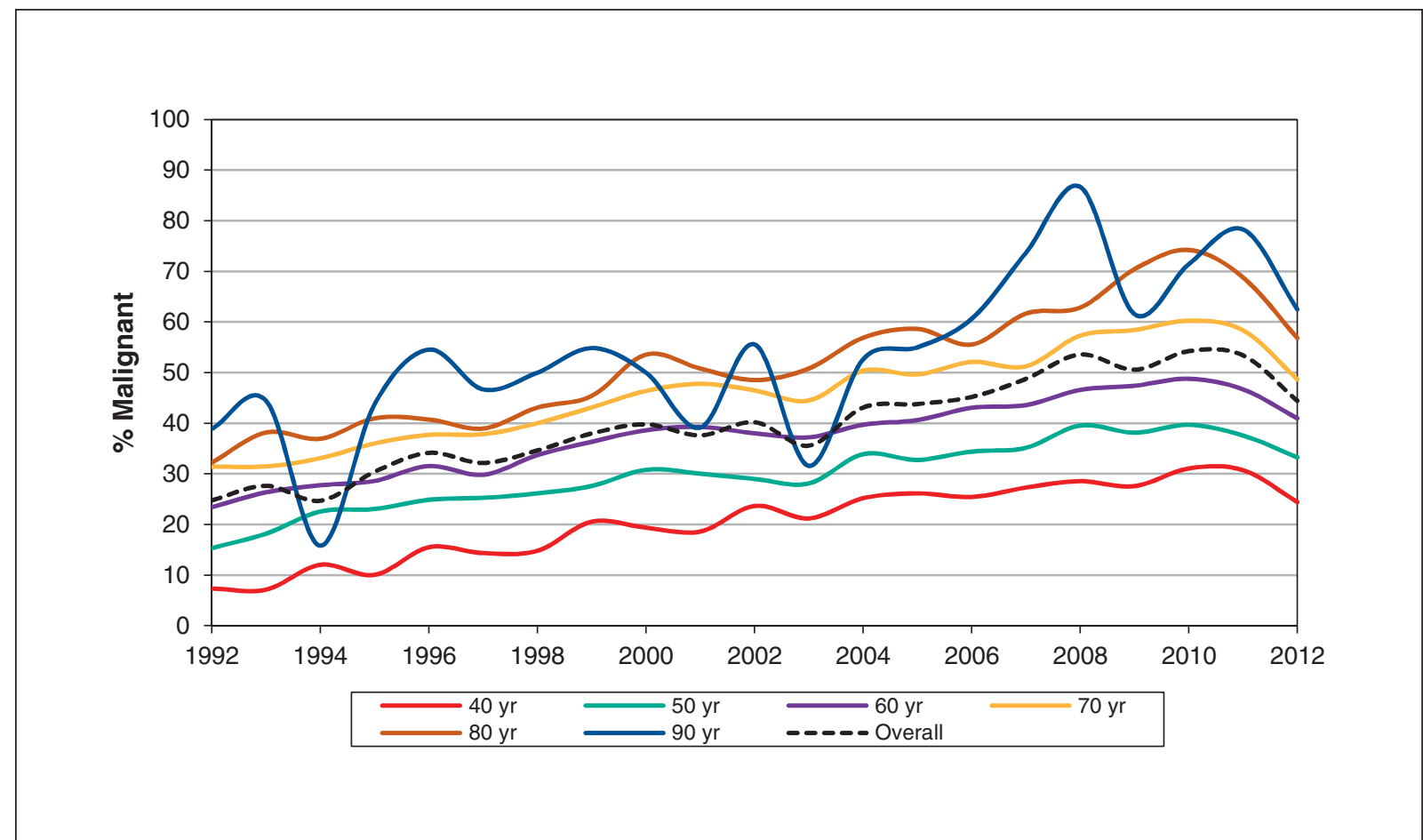

Figure 3: Proportion of prostate biopsies that showed malignant disease in Ontario, 1992-2012. Note: Lines between years were smoothed with spline function.

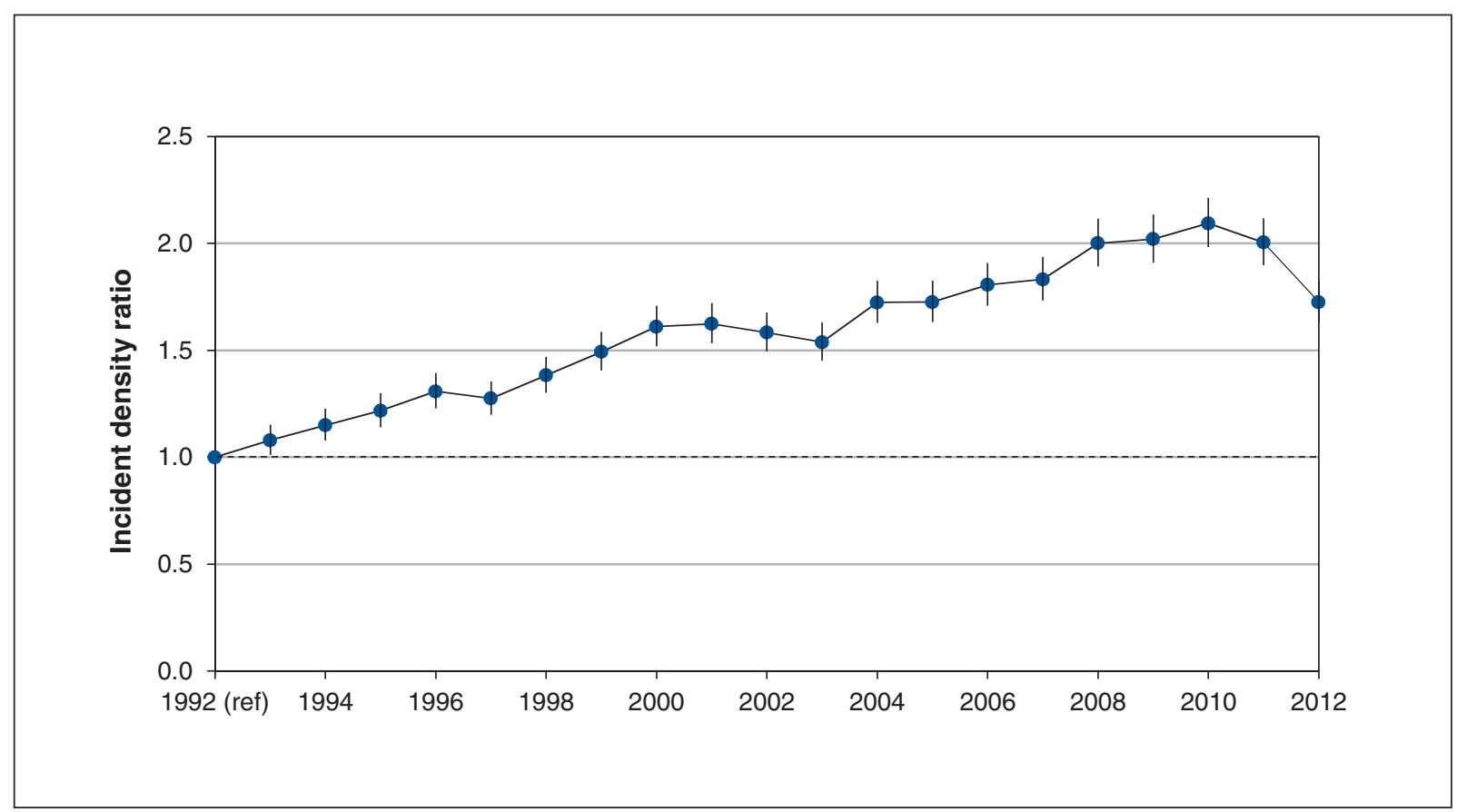

Figure 4: Annual age-adjusted proportion of prostate biopsies showing malignant disease in Ontario, 1992-2012. 
represented a larger proportion of patients receiving biopsy over time. For example, men aged 50-59 years represented $6 \%$ of biopsies in 1992 and $13 \%$ of biopsies in 2014. These trends are consistent with single-centre studies of biopsy use and studies of PSA screening. ${ }^{16,17}$ These changes were expected, because older men with comorbid medical conditions are less likely to benefit from screening for localized prostate cancer. ${ }^{18}$

We also sought to determine if the proportion of biopsies that resulted in a diagnosis of cancer changed over time. Men who receive biopsies should have a sufficiently high risk of malignant disease to warrant the potential adverse effects of the biopsy. Previous studies have identified clinical factors that increase malignancy risk on biopsy, and nomograms have been constructed to aid clinicians. ${ }^{7}$ We found the proportion of biopsies that showed malignant disease almost doubled during the study period, from $26 \%$ in 1992 to $49 \%$ in 2010 . This is noteworthy for several reasons. First, the increase occurred in conjunction with increasing biopsy rates. This provides some reassurance that increasing biopsy use was not exposing more men without cancer to the risks of biopsy. Second, the increased proportion occurred while prostate cancer rates in the United States decreased. ${ }^{19}$ Third, biopsies that showed malignant disease increased at the same time we observed decreased biopsy incidence in older men, who are at increased risk of malignant disease compared with younger men.

After 2010, we noted a decline in the proportion of biopsies that showed malignant disease - to $40 \%$ in 2012 . Because 2012 is the last year of data in this study, it is unclear if the recent decline is a chance finding or a reflection of true trends in patient selection. Notably, the decrease in malignant disease persisted when we adjusted for patient age, which suggests that the selection of younger men for biopsy in recent years does not explain this finding. The decrease in biopsy use and proportion of biopsies showing malignant disease suggest that cancers are likely being missed because patients are not undergoing screening or because selection methods for biopsy have changed. Studies that include information on prostate cancer grade and stage suggest that there has been a similar size in the decreased detection of low- and high-risk cancers since the US Preventive Services Task Force recommendation. ${ }^{12,16,20}$ If this finding is true in Ontario, it would suggest that the decrease in cancer detection is most likely because of decreased PSA screening.

\section{Limitations}

We are unable to determine the cause of changing biopsy trends. We observed decreased biopsy use since 2008, which coincides with the publication of randomized studies that suggested that prostate cancer screening does not benefit all men. These studies were followed by modifications to guidelines and a recommendation against prostate cancer screening. We cannot directly attribute changes in biopsy use to guideline changes; however, it is apparent that physicians in Ontario are responding to evolving data on this topic. Ontario has universal health coverage, and we cannot determine if the changes we saw are generalizable to other health care settings.
We are unable to comment on the clinical significance of detected cancers, because cancer grade and stage are not available in our data set. Although we interpreted the increase in the rate of biopsies showing malignant disease to suggest physicians were doing a better job of selecting patients for biopsy, it is possible that the increase was caused by more indolent tumour detection.

The sensitivity of the code we used to identify prostate biopsy varied over time. Changes in code sensitivity could falsely show a change in incidence that is due to the code rather than to practice change. We explored this possibility by calculating a code sensitivity adjusted incidence rate and found identical trends.

Our data sets start in 1992, therefore we could not determine if some men in our cohort received a biopsy or cancer diagnosis before 1992. Although this could change incidence calculations in early years of this study, it is unlikely to affect the trends we saw.

\section{Conclusion}

We found the incidence of prostate biopsy decreased in 2008 and 2012 in conjunction with changes to recommendations for prostate cancer screening. Repeat analyses of population-based data sets from Ontario and other jurisdictions are needed. Health care providers and administrators may use these data to understand physician behaviour and identify trends that require attention via policy change or education.

\section{References}

1. Siegel RL, Miller KD, Jemal A. Cancer statistics, 2015. CA Cancer 7 Clin 2015;65:5-29.

2. Tarone RE, Chu KC, Brawley OW. Implications of stage-specific survival rates in assessing recent declines in prostate cancer mortality rates. Epidemiology 2000;11:167-70.

3. Andriole GL, Crawford ED, Grubb RL III, et al. Prostate cancer screening in the randomized Prostate, Lung, Colorectal, and Ovarian Cancer Screening Trial: mortality results after 13 years of follow-up. 7 Natl Cancer Inst 2012;104:125-32.

4. Schröder FH, Hugosson J, Roobol MJ, et al. ERSPC Investigators. Prostatecancer mortality at 11 years of follow-up. N Engl 7 Med 2012;366:981-90.

5. Moyer VA; U.S. Preventive Services Task Force. Screening for prostate cancer: U.S. Preventive Services Task Force recommendation statement. Ann Intern Med 2012;157:120-34.

6. Canadian Task Force on Preventive Health Care; Bell N, Connor Gorber S, Shane A, et al. Recommendations on screening for prostate cancer with the prostate-specific antigen test. CMA7 2014;186:1225-34.

7. Nam RK, Toi A, Klotz LH, et al. Assessing individual risk for prostate cancer. 7 Clin Oncol 2007;25:3582-8.

8. Lavallée LT, Manuel DC, van Walraven C. Survival of men with prostate cancer undergoing radical prostatectomy in Ontario. 7 Urol 2014;192:1385-9.

9. Lavallée LT. Temporal changes in prostate biopsy use in Ontario. Ottawa: University of Ottawa; 2016. Available: www.ruor.uottawa.ca/handle/10393/34270 (accessed 2016 Feb. 16).

10. CANSIM - Canadian socioeconomic database from Statistics Canada. Ottawa: Statistics Canada; 2015. Available: www5.statcan.gc.ca/cansim/home-accueil ?lang=eng (accessed 2015 May 9).

11. U.S. Preventive Services Task Force. Screening for prostate cancer: U.S. Preventive Services Task Force recommendation statement. Ann Intern Med 2008;149:185-91.

12. Barocas DA, Mallin K, Graves AJ, et al. The effect of the USPSTF grade D recommendation against screening for prostate cancer on incident prostate cancer diagnoses in the United States. F Urol 2015;194:1587-93.

13. Cohn JA, Wang CE, Lakeman JC, et al. Primary care physician PSA screening practices before and after the final U.S. Preventive Services Task Force recommendation. Urol Oncol 2014;32:41.e23-30.

14. Hjertholm P, Fenger-Grøn M, Vestergaard M, et al. Variation in general practice prostate-specific antigen testing and prostate cancer outcomes: an ecological study. Int 7 Cancer 2015;136:435-42. 
15. Lee SY, Friderici J, Stefan MS, et al. Impact of the 2008 U.S. Preventative Services Task Force recommendation on frequency of prostate-specific antigen screening in older men. 7 Am Geriatr Soc 2014;62:1912-5.

16. Bhindi B, Mamdani M, Kulkarni GS, et al. Impact of the U.S. Preventive Services Task Force recommendations against prostate specific antigen screening on prostate biopsy and cancer detection rates. F Urol 2015;193:1519-24.

17. Howard DH, Tangka FK, Guy GP, et al. Prostate cancer screening in men ages 75 and older fell by 8 percentage points after Task Force recommendation. Health Aff (Millwood) 2013;32:596-602.

18. Albertsen PC, Hanley JA, Fine J. 20-year outcomes following conservative management of clinically localized prostate cancer. FAMA 2005;293: 2095-101.

19. Edwards BK, Noone A-M, Mariotto AB, et al. Annual Report to the Nation on the status of cancer, 1975-2010, featuring prevalence of comorbidity and impact on survival among persons with lung, colorectal, breast, or prostate cancer. Cancer 2014;120:1290-314.

20. Banerji JS, Wolff EM, Massman JD III, et al. Prostate needle biopsy outcomes in the era of the U.S. Preventive Services Task Force recommendation against prostate specific antigen based screening. F Urol 2016;195:66-73.

Affiliations: Division of Urology (Lavallee), Department of Surgery, Ottawa Hospital Research Institute and Institute of Clinical Evaluative
Sciences; Division of Urology (Breau), Department of Surgery, Ottawa Hospital Research Institute; Ottawa Hospital Research Institute (Fergusson); and Department of Medicine (van Walraven), Ottawa Hospital Research Institute, Ottawa, Ont.

Contributors: All authors have contributed substantially to this study.

Disclaimer: This study was supported by the Institute for Clinical Evaluative Sciences (ICES), which is funded by an annual grant from the Ontario Ministry of Health and Long-Term Care (MOHLTC). The opinions, results and conclusions reported in this paper are those of the authors and are independent from the funding sources. No endorsement by ICES or the Ontario MOHLTC is intended or should be inferred. Parts of this material are based on data and information compiled and provided by Canadian Institute for Health Information (CIHI). However, the analyses, conclusions, opinions and statements expressed herein are those of the author, and not necessarily those of CIHI.

Supplemental information: For reviewer comments and the original submission of this manuscript, please see www.cmajopen.ca/content/4/4/ E698/suppl/DC1 